Article

\title{
Research on Carbon Emissions of Electric Vehicles throughout the Life Cycle Assessment Taking into Vehicle Weight and Grid Mix Composition
}

\author{
Yanmei Li, Ningning Ha *(-) and Tingting Li \\ Department of Economics and Management, North China Electric Power University, Baoding 071000, China; \\ yanmei.li@ncepu.edu.cn (Y.L.); 15531811632@163.com (T.L.) \\ * Correspondence: 15732113447@163.com; Tel.: +86-10-752-5125
}

Received: 15 August 2019; Accepted: 18 September 2019; Published: 21 September 2019

\begin{abstract}
To study the impact of the promotion of electric vehicles on carbon emissions in China, the full life carbon emissions of electric vehicles are studied on the basis of considering such factors as vehicle weight and grid mix composition, and fuel vehicles are added for comparison. In this paper, we collect data for 34 domestic electric vehicles, and linear regression analysis is used to model the relationship between vehicle weight and energy consumption. Then, a Hybrid Life Cycle Assessment method is used to establish the life cycle carbon emission calculation model for electric vehicles and fuel vehicles. Finally, the life cycle carbon emissions of electric vehicles and fuel vehicles under different electrical energy structures are discussed using scenario analysis. The results show that under the current grid mix composition in China, the carbon emissions of electric vehicles of the same vehicle weight class are $24 \%$ to $31 \%$ higher than that of fuel vehicles. As the proportion of clean energy in the grid mix composition increases, the advantages of electric vehicles to reduce carbon emissions will gradually emerge.
\end{abstract}

Keywords: vehicle weight; grid mix composition; electric vehicle; life cycle assessment; carbon emissions

\section{Introduction}

Due to the reduction of exhaust emissions during driving, electric vehicles are used by more and more countries to promote low-carbon development and traffic emission reduction. Major developed countries in the world have successively put forward the development strategies for electric vehicles [1]. To comply with the global trend of electric vehicle development, reduce automobile carbon dioxide emissions, improve air quality and reduce dependence on international oil, China has taken the development of electric vehicles as one of its national strategies [2]. According to The Global Electric Vehicle Vision 2018 [3] released by the International Energy Agency, the global electric vehicles reached 3109.05 thousand in 2017, and is expected to reach 13 million in 2020 and nearly 130-228 million in 2030. By the end of 2018, China's electric vehicles reached 2.61 million, accounting for $1.09 \%$ of the total number of vehicles. In 2030, China's electric vehicle market share will reach 26-40\% [3].

For the research on the whole life cycle carbon emission assessment of electric vehicles, foreign countries have put forward relevant methods which are being constantly improved [4]. At present, the mature LCA models in other countries include GREET and e-balance; in the automobile field, it also includes models built with GaBi 6 software, EIO-LCA model of university of Toronto, DfE model of Mercedes-Benzes, etc. [5].

In China, the research on the application of full Life Cycle Assessment in the field of automobile started in the early 21st century [6,7]. Around 2010, with the start and development of electric vehicles 
in China, Ou Xunmin et al. [8,9] used the Life Cycle Assessment theory to compare the carbon emission and environmental impact of coal-electric vehicles with traditional fuel vehicles, proposed the China Tsinghua-CA3EM model, and found that electric cars can save more than $35 \%$ energy and reduce emissions by about $20 \%$ compared with fuel cars. Shi Xiaoqing $[10,11]$ et al. believed that according to different power supply scenarios, all-electric vehicles can achieve emissions reductions of $57 \%$ to $81.2 \%$.

However, some experts and scholars think that the emission reduction effect of electric vehicles is not obvious, and they may even increase the greenhouse gas emission under the influence of the current high-carbon electricity. For example, Song Yonghua et al. [12] thought that the development of electric vehicles is high carbon in terms of the national average carbon emissions from power terminals. Zhang Lei et al. [13] believed that the full life cycle comprehensive environmental impact of electric vehicle power system was $60.15 \%$ higher than that of internal combustion engine vehicle power system. Feng Chao et al. [14] thought that in the current grid mix composition and technical conditions, although electric cars had high energy efficiency and good oil substitution, their higher lifetime coal consumption would result in higher greenhouse gas emissions than conventional gasoline vehicles, in this case, large-scale development of the electric car is not good for greenhouse gas emissions.

In summary, domestic and foreign experts and scholars have carried out research on the full life cycle carbon emission of electric vehicles, but there is still a dispute on whether it is beneficial to reduce carbon emissions. Domestic scholars pay more attention to the research of whole-life cycle carbon emission model, but ignore the fact that China, as a big producer and seller of electric vehicles, produces electric vehicles with different vehicle weights, battery capacities and ranges, and different carbon emissions over the whole life cycle $[15,16]$. Therefore, it is of great significance to study the effects of vehicle weight, battery capacity and cruising range on carbon emission and environment. Meanwhile, the grid mix composition is also an important factor affecting the carbon emission of electric vehicles [17]. Therefore, it is also necessary to perform a comparative analysis of the influence of grid mix composition on the carbon emission of electric vehicles [18].

To study the impact of the promotion of electric vehicles on carbon emissions, this paper studies the full life cycle carbon emissions of electric vehicles, and makes a comparison with the full life cycle carbon emissions of fuel vehicles [19]. In this paper, we use a hybrid life cycle assessment method to calculate the carbon emissions of vehicles. The Hybrid Life Cycle Assessment (HLCA) combines the advantages of the Process-based Life Cycle Assessment (PLCA) with the Economic Input-Output Life Cycle Assessment (EIO LCA), which made the boundary more complete and the results more accurate. In addition to this, it can significantly reduce the truncation error. To conduct a more accurate study on the emission reduction effect of electric vehicles, this paper intends to use the HLCA method to calculate the energy consumption and greenhouse gas emissions of electric vehicles.

The primary objective of this paper is to study the impact of vehicle weight and gird mix composition changes on the life cycle carbon emissions of electric vehicles in China. For this purpose, we compare the life cycle carbon emissions of the same class electric vehicles and fuel vehicles. A second objective is to find out whether the development of electric vehicles in China can help reduce emissions under the current conditions. The final objective is to explore the carbon emission proportion for each phase of the life cycle of electric vehicles and fuel vehicles, which may help to develop an emission reduction policy for vehicles.

\section{Research Methods}

At first, this paper uses the linear regression analysis to verify the relationship between vehicle weight and energy consumption of $100 \mathrm{~km}$, and then the Hybrid Life Cycle Assessment method is used to calculate energy consumption and greenhouse gas emissions through Tinghua-CA3EM [8] model built by Ou Xunmin et al. and with the same grade of fuel car for comparative analysis. Finally, the scenario analysis of the full life cycle carbon emissions of electric vehicles and fuel vehicles under the grid mix composition in 2020, 2030 and 2050 is conducted. 


\subsection{Linear Regression Analysis}

First of all, the functional relationship between the vehicle weight and energy consumption of $100 \mathrm{~km}$ is established through the existing data of electric vehicles, and relevant parameters are obtained accordingly. Furthermore, four electric vehicle models are obtained by modeling electric vehicles. To understand the general situation of electric vehicles in China and determine the vehicle models to be evaluated, this paper collected data of 34 popular all-electric vehicles in the Chinese market(The parameters of the 34 electric vehicles are shown in Table A1), such as models, power types, vehicle weight, power consumption of $100 \mathrm{~km}$, battery capacity and range. For conventional vehicles, the whole vehicle weight and energy consumption are strongly coupled [20], so the functional relationship between the whole vehicle weight of these 34 models and the power consumption of $100 \mathrm{~km}$ is obtained (as shown in Figure 1). Although energy consumption is affected by many technical characteristics other than vehicle quality [21], we can assume a linear regression curve. Through linear regression analysis and testing, it is verified that there is a linear relationship between the energy consumption of $100 \mathrm{~km}$ and the vehicle weight: $\mathrm{y}=0.0051 \mathrm{x}+6.0576$, and the determination coefficient $\mathrm{R}^{2}=0.951$, which proves that the model fits well. From the slope of the linear regression curve, it can be known that every $100 \mathrm{~kg}$ increase in the vehicle weight will increase the energy demand of electric vehicle by $0.0051 \mathrm{kWh} / \mathrm{km}$.

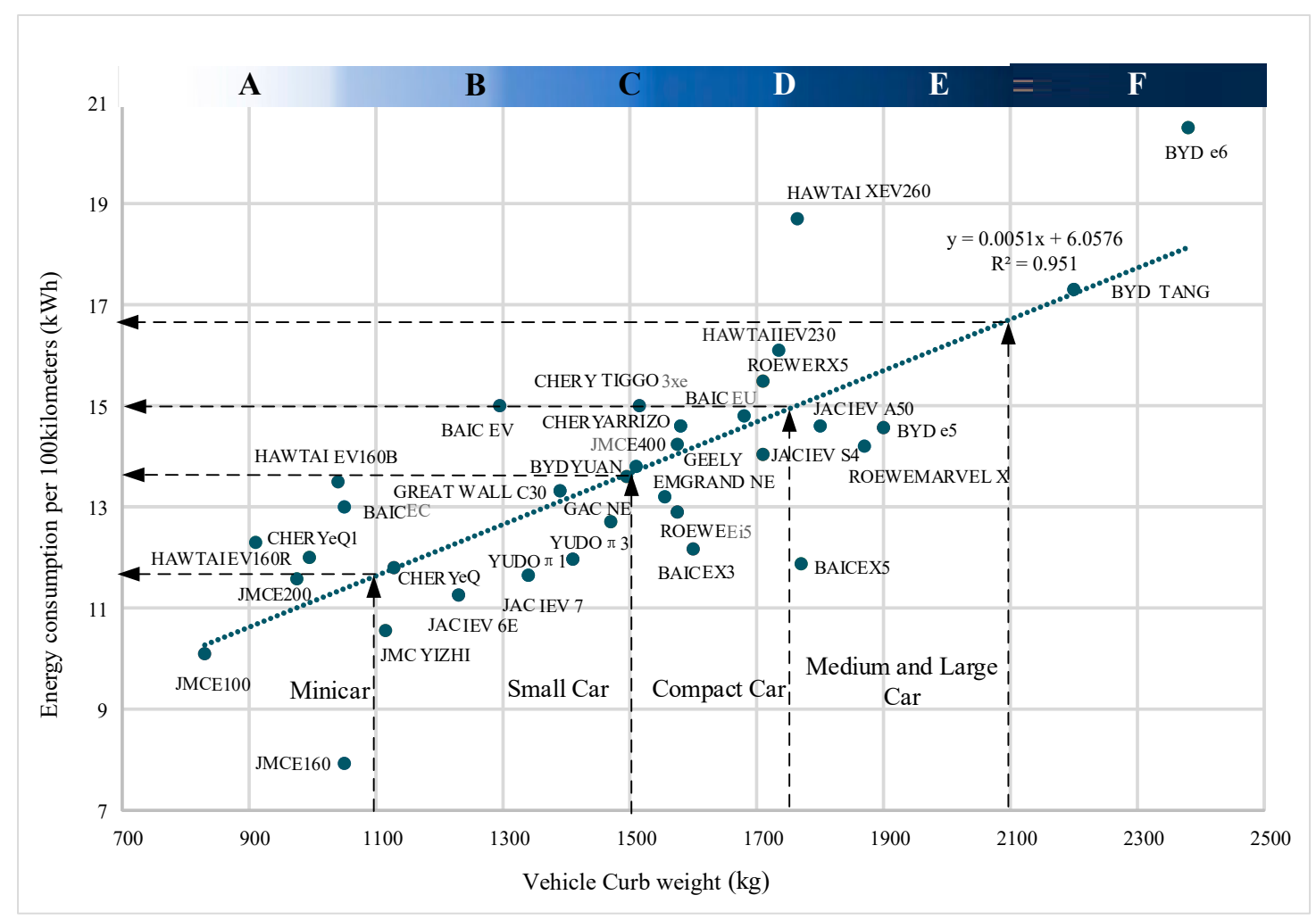

Figure 1. The relationship between electric vehicle energy consumption and vehicle weight.

Because China has no electric vehicle classification standard at present, in this paper, with reference to the classification standards in European and American countries and based on the electric car manufacturers of electric vehicles from the classification (classification data from the Pacific automotive network), four types of electric vehicles are modeled: mini car (segment A), small car (segment C), compact car (segment D), medium and large car (segment F). According to the regression equation, once the vehicle weight is determined, the 100-km energy consumption demand of the electric vehicle can be determined, and the appropriate battery capacity and range can be determined [9]. To calculate the total energy demand of electric vehicles, we assume that the charging efficiency of electric vehicles 
is $96 \%$ and the battery efficiency is $95 \%$ [15]. Related parameters of this model are shown in Table 1 . After modeling and determining parameters, relevant data can be collected and life-cycle carbon emission calculation can be carried out.

Table 1. Basic parameters of different levels of electric vehicles.

\begin{tabular}{|c|c|c|c|c|}
\hline Classification & $\begin{array}{l}\text { The Vehicle } \\
\text { Weight (kg) }\end{array}$ & $\begin{array}{l}\text { Battery Capacity } \\
(\mathbf{k W h})\end{array}$ & Range (km) & $\begin{array}{l}\text { Energy Consumption per } \\
100 \mathrm{~km}(\mathrm{kWh} / 100 \mathrm{~km})\end{array}$ \\
\hline Segment A-mini car & 1100 & 17.7 & 151 & 11.67 \\
\hline Segment C—small car & 1500 & 24.4 & 177 & 13.71 \\
\hline Segment D—compact car & 1750 & 42.1 & 281 & 14.98 \\
\hline $\begin{array}{l}\text { Segment } \mathrm{F}-\text { medium } \\
\text { and large car }\end{array}$ & 2100 & 59.9 & 357 & 16.77 \\
\hline
\end{tabular}

\subsection{Hybrid Life Cycle Assessment}

According to different system boundaries and principles, Life Cycle Assessment methods can be divided into process-based Life Cycle Assessment (PLCA), input-output Life Cycle Assessment (EIO LCA) and Hybrid Life Cycle Assessment (HLCA).Hybrid Life Cycle Assessment is a method combining PLCA and EIO-LCA, which cannot only eliminate the truncation error of PLCA, but also overcome the weakness of weak pertinence of EIO LCA, and also bring the use and scrapping stage of products into the evaluation scope [22]. HLCA is mainly divided into three forms: hierarchical, split input-output sectors and integrated mixed analysis, according to the data availability and accuracy, this paper adopts hierarchical HLCA. The direct emission of each stage is calculated by PLCA method, while the indirect emission is calculated by EIO-LCA. Greenhouse gas emissions in the whole life cycle are the sum of direct and indirect emissions in each sub-phase [23].

According to the usage conditions and scenarios of PLCA and EIO LCA [22,24,25], the boundary between PLCA and EIO LCA in the HLCA model of the full Life Cycle Assessment of electric vehicles is divided: in the research of the full life cycle of the fuel of electric vehicles, the PLCA method is directly adopted; in the study of the whole life cycle of electric vehicles, the production process of vehicles is decomposed. EIO LCA method is adopted in the upstream process from raw material mining to parts production, and PLCA method is adopted in the stage of vehicle assembly, production, transportation and final scrapping.

\subsection{Evaluation Objectives and System Boundaries}

In the past, the boundary of vehicle Life Cycle Assessment system was mainly defined as fuel cycle material cycle [5], fuel cycle and vehicle cycle [26], with reference to the selection of whole life cycle of the past boundary, the evaluation boundary in this paper includes fuel cycle and vehicle cycle, and the life cycle process covers the production stage, use stage and scrap stage of the whole life cycle (Figure 2).

1. Fuel cycle: The analysis is based on the full grid mix, which includes coal-fired power generation and other power generation forms. The system boundary includes the production and transportation of electricity. For example, the coal-fired power generation include the processes from coal mining and transportation to power plants, power generation processes and power transmission processes to charging piles and the consumption process of vehicles. Because our country electric grid mix composition including other power generation methods except coal, water power, wind power, solar power, nuclear power, etc. They generate electricity with different carbon emissions and environmental impacts; therefore, this article will fully consider these power generation methods, according to the proportion of 2017 years of Chinese electric grid mix composition energy (source: China statistical yearbook, 2018). In contrast, the fuel cycle of a fuel truck includes the extraction, transportation to a chemical plant, refining, transportation to a gas station and consumption of fuel truck. 
2. Vehicle cycle: vehicle cycle includes the mining of raw materials, production and assembly of parts, use and scrap of electric vehicles. As there are many similar processes in the process of production, maintenance in the process of use, parts replacement and final scrapping, the vehicle maintenance parts with small energy consumption and emission are ignored in this paper for the whole life cycle.

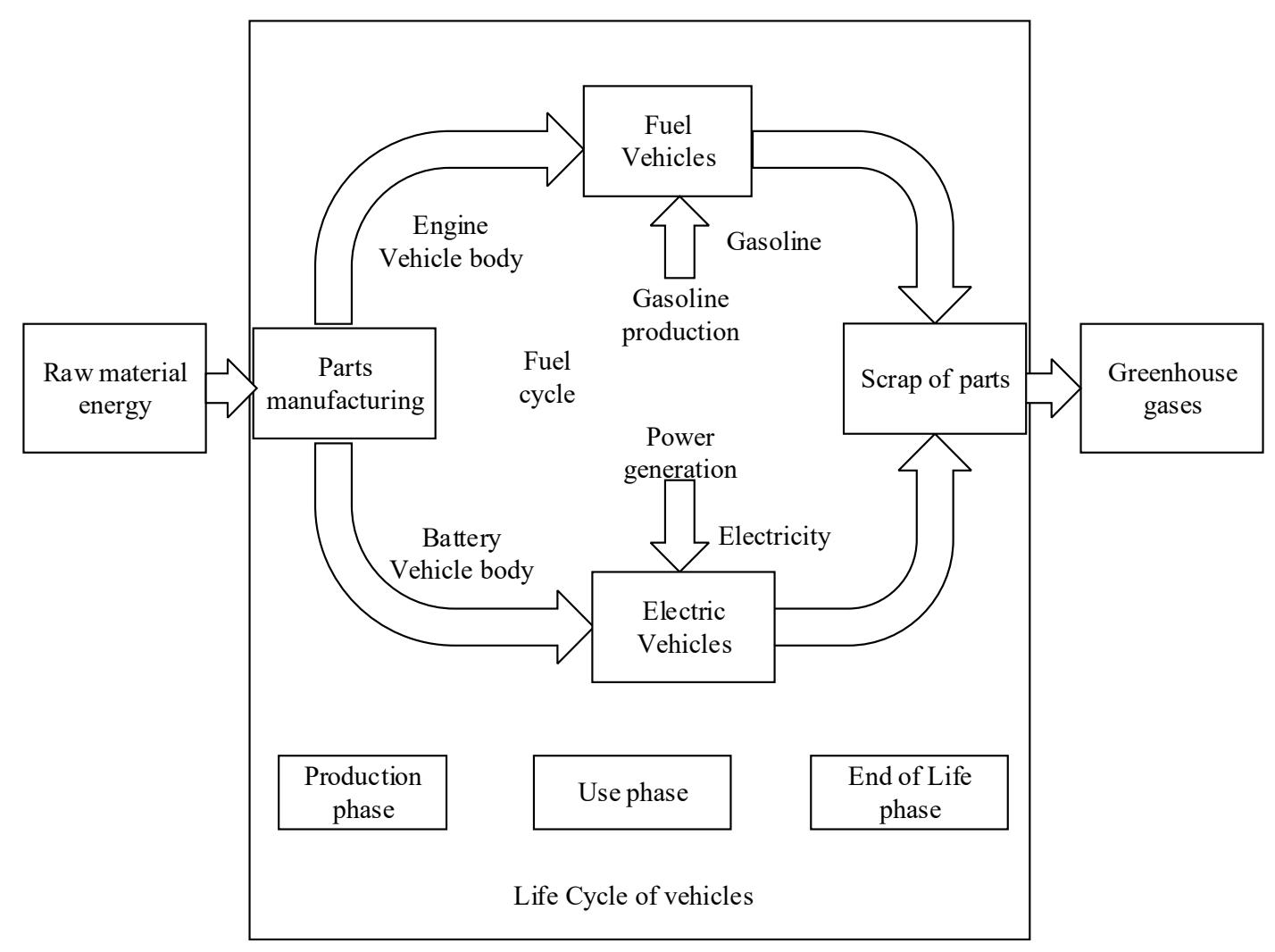

Figure 2. System boundary of Life Cycle Assessment for electric vehicles and fuel vehicles.

\subsection{Greenhouse Gas Emission Calculation Model}

When selecting the calculation model of greenhouse gas emissions, taking into account the characteristics of China, this paper selects the Tinghua-CA3EM model proposed by Ou Xunmin [9] and others for calculation.

The model first calculates the emissions of $\mathrm{CO}_{2}, \mathrm{CH}_{4}$ and $\mathrm{N}_{2} \mathrm{O}$ in each process, and finally converts them into $\mathrm{CO}_{2}$ equivalent according to the Global Warming Potential (GWP). According to the results of the fifth assessment report of the Intergovernmental Panel on Climate Change (IPCC), the GWP of $\mathrm{CH}_{4}$ and $\mathrm{N}_{2} \mathrm{O}$ are 34 and 298, respectively [27].

The total equivalent of greenhouse gas emission of the $j$ th type of energies is denoted as $\mathrm{G}_{j}(j=1$, $\ldots, 7), \mathrm{CO}_{2}, \mathrm{CH}_{4}$ and $\mathrm{N}_{2} \mathrm{O}$ emissions of the $j$ th type of energies are denoted as $\mathrm{CO}_{2, j}, \mathrm{CH}_{4, j}, \mathrm{~N}_{2} \mathrm{O}_{j}$, then:

$$
\mathrm{G}_{j}=\mathrm{CO}_{2, j}+34 \times \mathrm{CH}_{4, j}+298 \times \mathrm{N}_{2} \mathrm{O}_{j} .
$$

The lifecycle emissions of each particular type of greenhouse gas can be calculated by adding the direct emission intensity of upstream emissions and the process fuels (electricity, diesel, gasoline, etc.) used throughout the process. Take $\mathrm{CO}_{2}$ emissions generated by coal power generation in power plants as an example:

$$
\begin{gathered}
\mathrm{CO}_{2, \text { coal }}=E N_{\text {coal }}\left(\mathrm{CO}_{2, \text { upstream coal }}+\mathrm{CO}_{2, \text { direct }}\right), \\
\mathrm{CO}_{2, \text { direct }}=\frac{44}{12} C C_{\text {coal }} F O R_{\text {coal }} \mathrm{CO}_{2, \text { coal }} .
\end{gathered}
$$


$\mathrm{CO}_{2 \text {,upstream coal }}$ is the upstream $\mathrm{CO}_{2}$ coal emission factor $(\mathrm{g} / \mathrm{MJ}), \mathrm{CO}_{2 \text {,direct }}$ is the direct $\mathrm{CO}_{2}$ emission factor (g/MJ) of coal as fuel, $\mathrm{CC}_{\text {coal }}$ is the carbon content $(\mathrm{g} / \mathrm{MJ})$ of coal, $F O R_{\text {coal }}$ is the carbon oxygen content rate of coal.

Among them,

$$
E N_{\text {coal }}=\frac{S H_{\text {coal }}}{\eta_{\text {power plant }}}
$$

where $E N_{\text {coal }}$ is the amount of coal used in the factory for each MJ of final power generation, $S H_{\text {coal }}$ is the proportion of coal in the total power generation; $\eta_{\text {power plant }}$ is the energy efficiency of coal-fired power plants. Similarly, $\mathrm{CH}_{4}$ and $\mathrm{N}_{2} \mathrm{O}$ emissions are calculated accordingly.

Taking into account the production time and location of PV modules and wind turbines, Dr. Wilfried van Sark [28] calculated and found that the carbon emissions per kWh of photovoltaic and wind power generation is only $1 / 10$ to $1 / 20$ of fossil energy in 2015. There is an overwhelming advantage for renewable power generation in reducing carbon emissions. Overall, whenever the installed capacity of clean energy doubles, the energy consumption of PV modules and wind turbines will drop by about $12 \%$, and carbon emissions will fall by $17-24 \%$ [28]. As the proportion of clean energy increases and production technology advances, carbon emissions from renewable energy generation will be greatly reduced. Therefore, in the calculation of carbon emissions, carbon emissions from renewable power generation could be negligible.

\section{Data Collection}

The calculation process of carbon emission in the whole life cycle of automobiles involves the collection of a large number of basic data. With reference to the existing literature, the data collected in this paper and their approaches are shown in Table 2.

Table 2. Data sources.

\begin{tabular}{cc}
\hline Data Name & Source \\
\hline Green House Gas (GHG) emission factor & IPCC [29], Guidelines for Compiling Provincial GHG \\
Inventory [30]
\end{tabular}

According to the "Introduction to the Operation of Renewable Energy Grid-Connected in 2018" [40], the "2018 National Electric Power Process Statistics Express List" [41], and the "National People's Republic of China 2018 National Economic and Social Development Gazette" [42] and Grid mix composition estimates based on national energy and power development strategy goals, the grid mix composition of China in 2020, 2030 and 2050 is shown in Figure 3 (The grid mix composition data of China is shown in Table A2). 


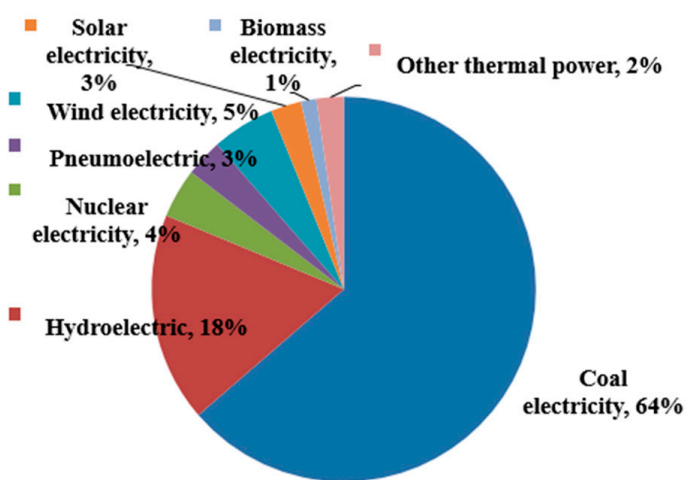

Grid Mix Composition in China in 2018

(a)

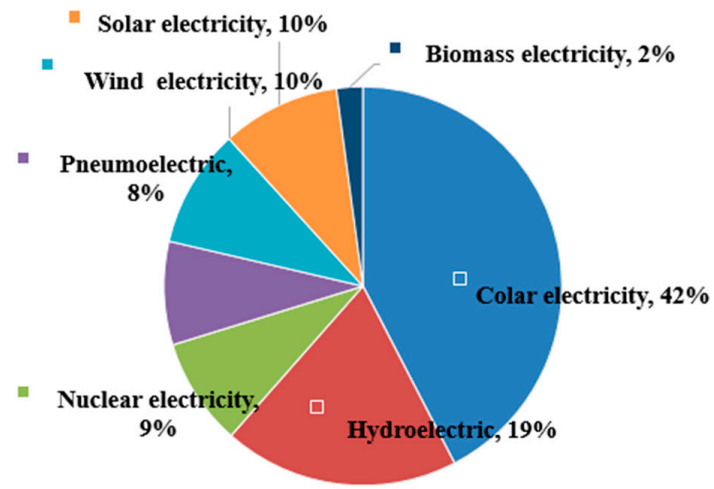

Grid Mix Composition in China in 2030

(c)

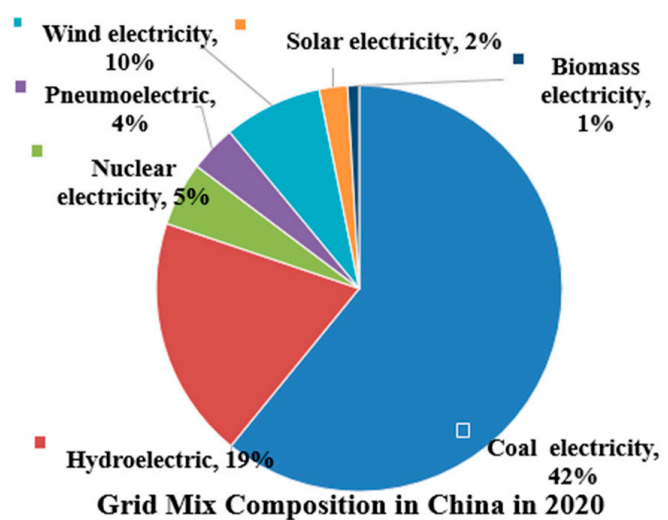

(b)

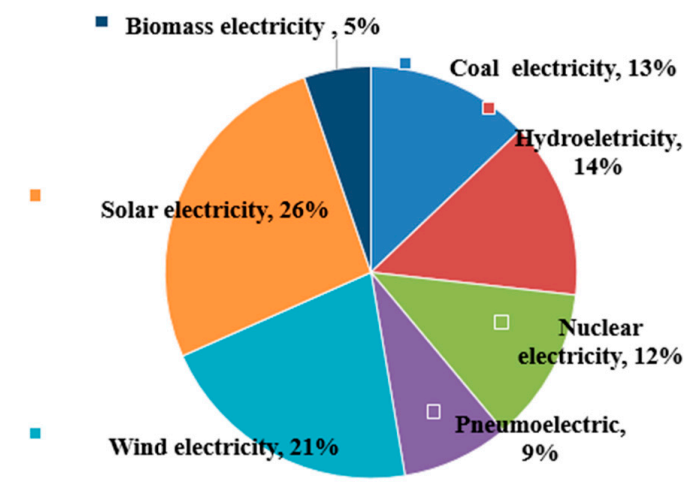

Grid Mix Composition in China in 2050

(d)

Figure 3. (a) China's grid mix composition and ratio in 2018; (b) China's grid mix composition and ratio forecast for 2020; (c) China's grid mix composition and ratio forecast for 2030; (d) China's grid mix composition and ratio forecast for 2050.

\section{Research Results}

\subsection{Carbon Emission Comparison between Electric Vehicles and Fuel Vehicles under the Current Electric Energy Structure}

Based on China's grid mix composition and ratio forecast for 2018, 2020, 2030 and 2050 and the model we built, the carbon emission of electric vehicles and fuel vehicles under the current Grid mix

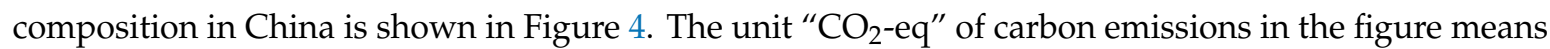
carbon dioxide equivalent. Figure 4 compares the greenhouse gas emissions of different vehicles over their whole life cycle. The solid line on the left of Figure 4 represents the carbon emission of electric vehicles, while the dotted line represents the carbon emission of fuel vehicles. The histogram shows the carbon emission of electric vehicles at all stages of their life cycle, which shows the impact in the production stage, use stage and treatment stage in a cumulative manner.

As can be seen from Figure 4, the carbon emission of the two kinds of cars is quite different in different life cycle stages. No matter how electric vehicles are configured, their carbon emission performance at the present stage is not as good as that of conventional fuel vehicles. In the production stage, electric cars are not as environmentally friendly as traditional fuel cars, because the production of battery system in the production stage produces more carbon emissions than the engine [43]. In the use phase, electric vehicles do not offset the carbon emissions in the production phase by reducing the carbon emissions in the use phase.

At the scrapping stage, the carbon emissions of electric cars are similar to those of electric cars. Throughout its life cycle, electric cars have higher carbon emissions than conventional fuel cars. 
In addition, the bigger the electric car, the more carbon it produces. Whether it is a traditional fuel car or an electric car, whether it is directly through fuel combustion or indirectly through electricity production, the carbon emission in the use stage is the main carbon emission in the whole life cycle. For the model adopted in this paper, the carbon emission of electric vehicles of any level is higher than that of conventional fuel vehicles. Among them, the carbon emission of A-class electric vehicles, C-class electric vehicles, D-class electric vehicles and F-class electric vehicles is 1.24 times, 1.26 times, 1.28 times and 1.31 times that of the fuel vehicles of the same grade. For the same model, the carbon emission of F-class electric vehicles is 1.25 times that of A-class electric vehicles, C-class electric vehicles and D-class electric vehicles are 1.16 times and 1.08 times, respectively. The carbon emission of A-class electric vehicles in the production, use and scrapping stages accounts for $8.5 \%, 90.8 \%$ and $0.5 \%$ of the whole life cycle, respectively. The carbon emission in the production, use and scrapping stages of C-class electric vehicles accounts for $9.5 \%, 89.9 \%$ and $0.6 \%$ of the whole life cycle, respectively.

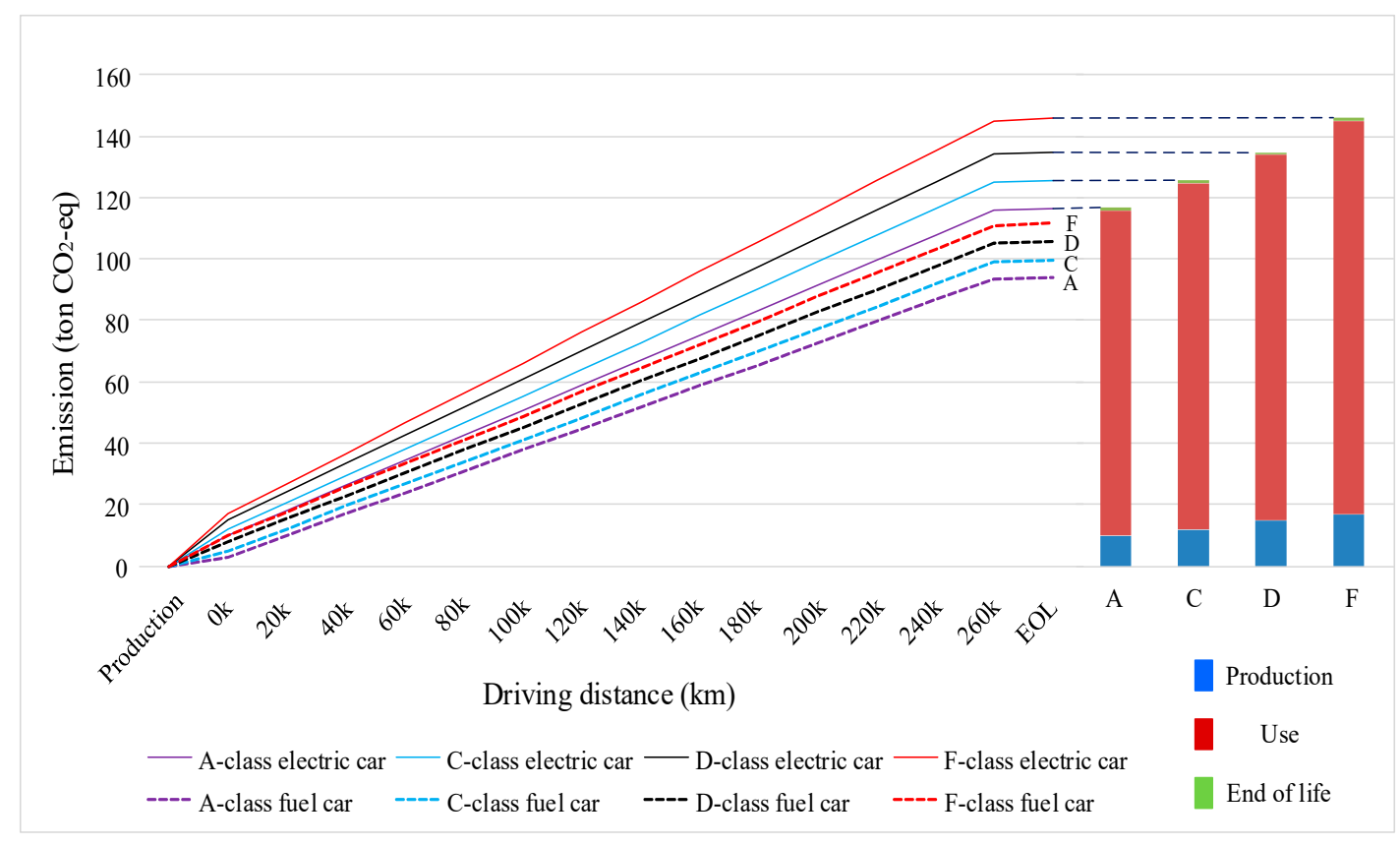

Figure 4. Comparison of life cycle carbon emissions between electric vehicles and fuel vehicles under the current grid mix composition.

\subsection{Carbon Emission Comparison between Electric Vehicles and Fuel Vehicles under Different Grid Mix Compositions}

Based on China's 2020, 2030 and 2050 electricity generation and its structure forecast, this paper makes a comparative analysis of the carbon emissions of electric vehicles and fuel vehicles.

With the development of clean energy, more and more coal power will be replaced by clean energy in the future. With the reduction of the proportion of coal power in the grid mix composition and the increase of the proportion of clean energy, the carbon emission intensity generated by electricity generation will be reduced, and the carbon emission caused by electricity generation will be reduced in the electric energy consumed by electric vehicles in the use stage [44-50]. Carbon emissions of electric vehicles and gasoline vehicles in the full life cycle under the predicted grid mix composition in 2020, 2030 and 2050. Results show that in 2020, under the grid mix composition of the electric car the whole life cycle of carbon emissions is still higher than fuel vehicles; in 2030, under the grid mix composition of the lifecycle carbon emissions of electric cars will be lower than for fuel vehicles; in 2050, under the grid mix composition of the lifecycle carbon emissions of electric cars will be much lower than fuel vehicle emissions. In these three cases, the full life cycle carbon emission of electric vehicles and gasoline vehicles of four levels is shown in Figure 5a-c. 


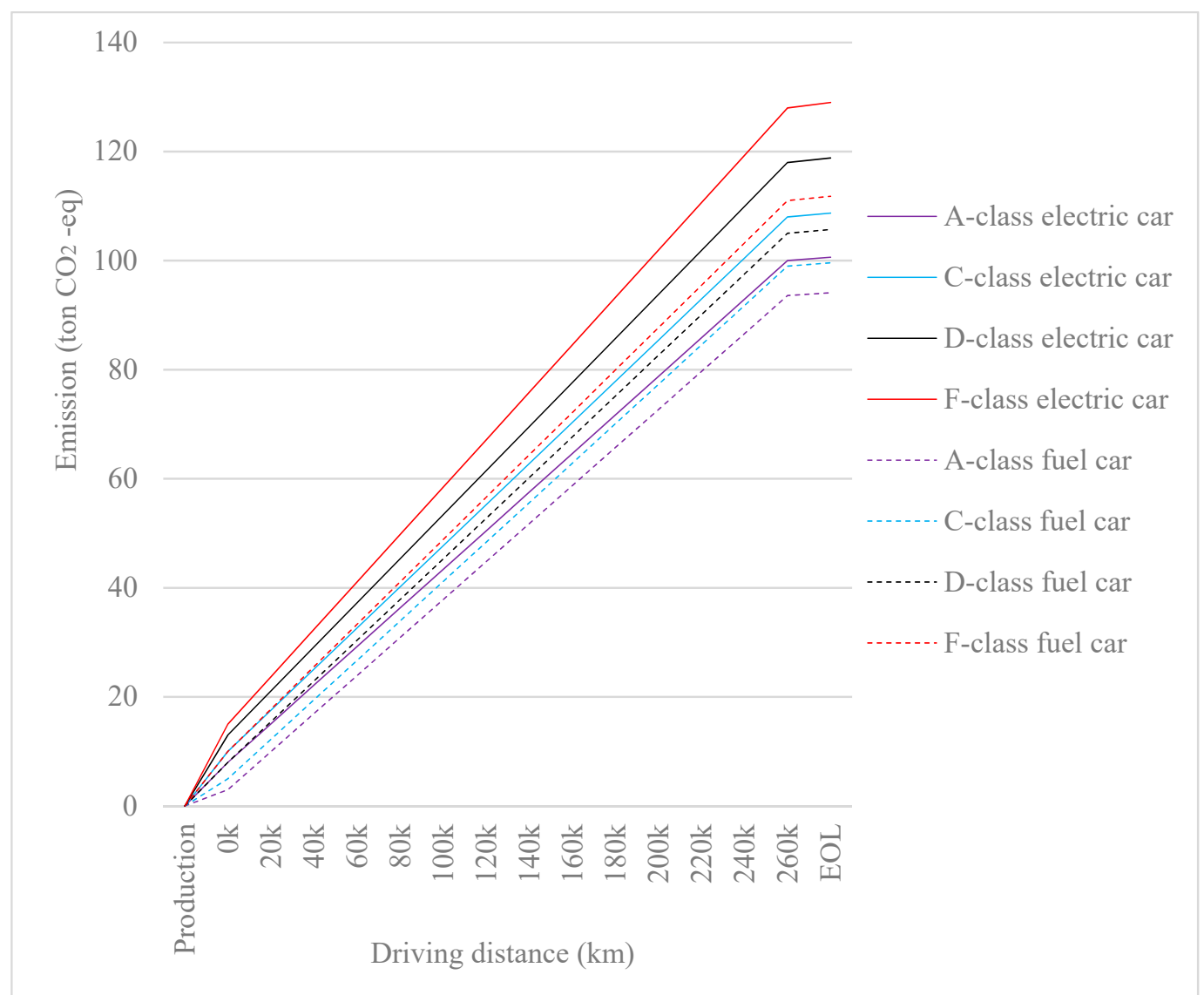

(a)

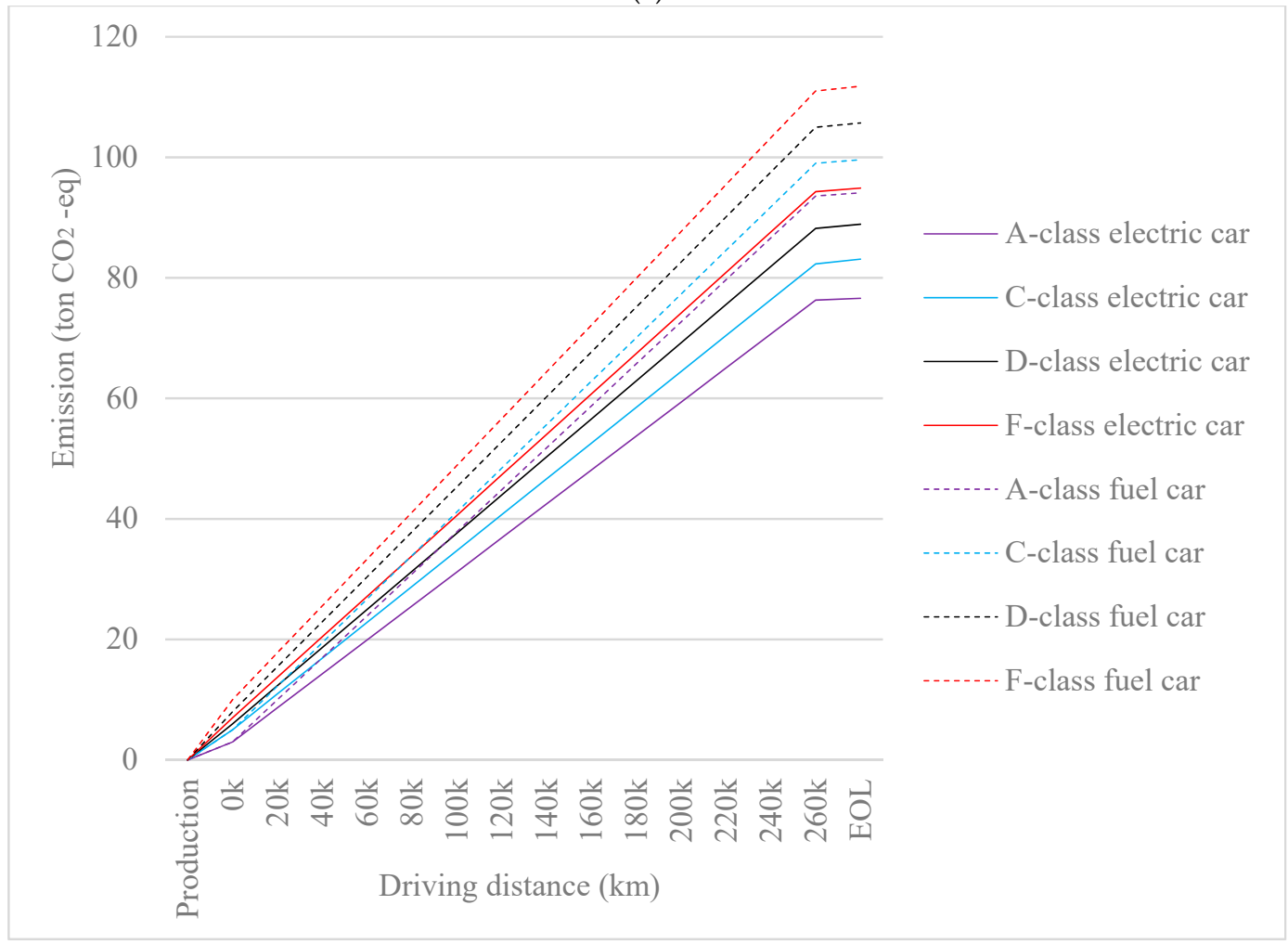

(b)

Figure 5. Cont. 


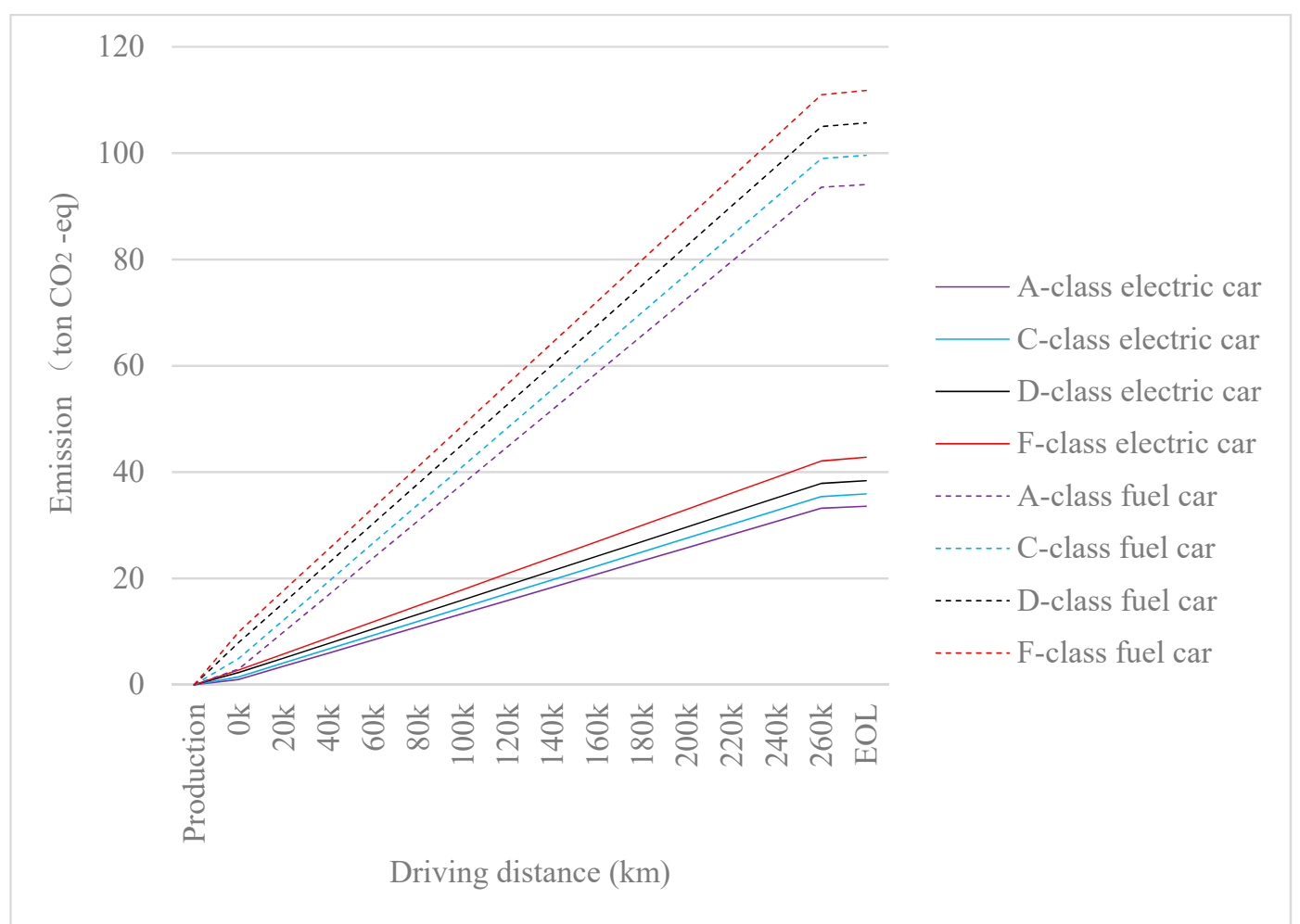

(c)

Figure 5. (a) Comparison of carbon emissions of two types of vehicles under the grid mix composition in 2020; (b) Comparison of carbon emissions of two types of vehicles under the grid mix composition in 2030; (c) Comparison of carbon emissions of two types of vehicles under the grid mix composition in 2050.

From Figure 5a-c, it can be concluded that under the power structure of 2020, 2030 and 2050, the carbon emission ratios of Electric Vehicles and fuel vehicles at various phases of the life cycle are shown in Table 3.

Table 3. Values of share for production phase, use phase and end of life phase of different vehicles.

\begin{tabular}{|c|c|c|c|c|c|c|c|c|c|}
\hline Year & \multicolumn{3}{|c|}{2020} & \multicolumn{3}{|c|}{2030} & \multicolumn{3}{|c|}{2050} \\
\hline $\begin{array}{l}\text { Phase } \\
\text { Vehicle Type }\end{array}$ & PP (\%) & UP (\%) & EOLP (\%) & PP (\%) & UP (\%) & EOLP (\%) & PP (\%) & UP (\%) & EOLP (\%) \\
\hline A segment EV & 7.95 & 92.05 & 0.62 & 3.92 & 96.08 & 0.39 & 2.98 & 97.02 & 1.19 \\
\hline$C$ segment EV & 9.20 & 90.80 & 0.66 & 6.02 & 93.98 & 0.96 & 4.18 & 95.82 & 1.39 \\
\hline D segment EV & 10.94 & 89.06 & 0.69 & 6.75 & 93.25 & 0.79 & 5.99 & 94.01 & 1.30 \\
\hline F segment EV & 11.63 & 88.37 & 0.78 & 7.38 & 92.62 & 0.63 & 6.54 & 93.46 & 1.64 \\
\hline A segment ICEV & 3.19 & 96.81 & 0.54 & 3.19 & 96.81 & 0.54 & 3.19 & 96.81 & 0.54 \\
\hline C segment ICEV & 5.02 & 94.98 & 0.60 & 5.02 & 94.98 & 0.60 & 5.02 & 94.98 & 0.60 \\
\hline D segment ICEV & 7.57 & 92.43 & 0.66 & 7.57 & 92.43 & 0.66 & 7.57 & 92.43 & 0.66 \\
\hline F segment ICEV & 8.94 & 91.06 & 0.72 & 8.94 & 91.06 & 0.72 & 8.94 & 91.06 & 0.72 \\
\hline
\end{tabular}

Note: PP means Production Phase, UP means Use Phase, EOLP means End of Life Phase.

According to the results, the carbon emissions of Electric Vehicles and fuel vehicles are mainly concentrated in the use phase. The use phase accounts for more than $90 \%$ of the life cycle carbon emissions for all types of vehicles. 


\section{Conclusions}

This paper collected the highest sales on the Chinese market by electric vehicle weight and hundreds of $\mathrm{km}$ of energy consumption data, and then modeling the relationship between the two variables, four levels of the electric car model, and based on vehicle weight to find the corresponding level of gasoline vehicles, and then the full Life Cycle Assessment model based on the analysis of the four different levels of the electric vehicle and fuel vehicle emissions, and based on the simulation analysis of the full life cycle carbon emission of electric vehicles and fuel vehicles in the electric grid mix composition in 2020, 2030 and 2050. The following conclusions are drawn:

1. Through the data collection and analysis of 34 electric models in China, it is found that there is a linear relationship between the whole weight of electric vehicles and the energy consumption of $100 \mathrm{~km}$. The larger the vehicle weight, the greater the energy consumption for $100 \mathrm{~km}$, and the greater the corresponding battery capacity and range. In the same life cycle, electric vehicles with large vehicle weight will consume more electricity and generate more carbon emissions than electric vehicles with small vehicle weight. The comparison of the carbon emission of electric vehicles and fuel vehicles shows that the full life cycle carbon emission of electric vehicles of any level is higher than that of fuel vehicles of the same level under the current energy structure. In addition, the lifetime carbon emissions of electric vehicles increase with the increase of vehicle weight.

2. It can be seen from the calculations that the energy consumption and pollutant emissions of the whole life cycle of the automobile mainly come from the use stage. Due to China's current grid mix composition still being dominated by coal, the electricity consumed during the electric vehicle use phase contains a large amount of carbon emissions, so the electric car relative to the fuel vehicle emission reduction effect is not obvious, and may even result in lifecycle carbon emissions that are more than those of fuel vehicles, which is consistent with the conclusions of Feng Chao [14] and Global Electric Vehicle Prospect 2018 [3]. There is some difference between the research results and those of Ou Xunmin et al. [9], who believe that the carbon emission of electric vehicles is less than that of fuel vehicles in their whole life cycle. The main reason is that the PLCA method selected by Ou Xunmin et al. may have truncation errors when selecting system boundaries.

3. Under the current grid mix composition, the carbon emissions of electric vehicles of the same level are higher than those of fuel vehicles over the whole life cycle. As clean energy increasingly replaces coal power, the relative carbon intensity of electric vehicles will be reduced. In the predicted electricity structure of 2020, the carbon emission of electric vehicles of the same level is higher than that of fuel cars, while in the electricity structure of 2030 and 2050, the carbon emission of electric vehicles of the same level is lower than that of fuel cars. This is mainly due to the lower production carbon emissions of the electricity consumed during the use of electric vehicles.

Author Contributions: Conceptualization, Y.L. and N.H.; methodology, N.H.; software, N.H.; validation, Y.L. and T.L.; formal analysis, N.H.; investigation, N.H.; resources, Y.L.; data curation, Y.L.; writing-original draft preparation, N.H.; writing-review and editing, T.L.; visualization, T.L.; supervision, Y.L.; project administration, Y.L.; funding acquisition, Y.L.

Funding: This research was funded by the National Natural Science Foundation of China, grant No.71964022.

Conflicts of Interest: The authors declare no conflict of interest. 


\section{Appendix A}

Table A1. The parameters of the 34 electric vehicles.

\begin{tabular}{|c|c|c|c|c|}
\hline $\begin{array}{lll} & \text { Parameter } \\
\text { Vehicle } & \end{array}$ & $\begin{array}{l}\text { Energy Consumption } \\
(\mathrm{kWh} / \mathbf{1 0 0 k m})\end{array}$ & $\begin{array}{l}\text { Vehicle Weight } \\
(\mathbf{k g})\end{array}$ & Drive Type & Vehicle Model \\
\hline Beiqi EC & 13 & 1050 & Pure electric & Mini car \\
\hline Beiqi EX3 & 12.17 & 1600 & Pure electric & SUV \\
\hline Beiqi EX5 & 11.88 & 1770 & Pure electric & SUV \\
\hline Beiqi EV & 15 & 1295 & Pure electric & Small car \\
\hline Beiqi EU & 14.8 & 1680 & Pure electric & Compact car \\
\hline BYD Yuan & 13.6 & 1495 & Pure electric & SUV \\
\hline BYD Tang & 17.3 & 2200 & Pure electric & SUV \\
\hline BYD e5 & 14.57 & 1900 & Pure electric & Compact car \\
\hline BYD e6 & 20.5 & 2380 & Pure electric & MPV \\
\hline Jianghuai IEV 6E & 11.26 & 1230 & Pure electric & Mini car \\
\hline Jianghuai IEV 7 & 11.65 & 1340 & Pure electric & Small car \\
\hline Jianghuai IEV S4 & 14.04 & 1710 & Pure electric & SUV \\
\hline Jianghuai IEV A50 & 14.6 & 1800 & Pure electric & Compact car \\
\hline Jiangling E100 & 10.1 & 830 & Pure electric & Mini car \\
\hline Jiangling E200 & 11.58 & 975 & Pure electric & Mini car \\
\hline Jiangling E160 & 7.93 & 1050 & Pure electric & Small car \\
\hline Jiangling E400 & 13.8 & 1510 & Pure electric & SUV \\
\hline Jiangling Yizhi & 10.56 & 1115 & Pure electric & Small car \\
\hline Chery Ayers5e & 14.6 & 1580 & Pure electric & Compact car \\
\hline Chery eQ & 11.8 & 1128 & Pure electric & Mini car \\
\hline Chery eQ1 & 12 & 995 & Pure electric & Mini car \\
\hline Chery Tiggo3xe & 15 & 1515 & Pure electric & SUV \\
\hline Roewe Ei5 & 13.2 & 1555 & Pure electric & Compact car \\
\hline Roewe RX5 & 15.49 & 1710 & Pure electric & SUV \\
\hline Roewe MARVEL X & 14.2 & 1870 & Pure electric & SUV \\
\hline Huatai EV160B & 13.5 & 1040 & Pure electric & Mini car \\
\hline Huatai EV160R & 12.3 & 910 & Pure electric & Mini car \\
\hline Huatai XEV260 & 18.7 & 1764 & Pure electric & SUV \\
\hline Huatai IEV230 & 16.1 & 1735 & Pure electric & Compact car \\
\hline Geely New Energy & 14.24 & 1575 & Pure electric & Compact car \\
\hline Changcheng C30 & 13.32 & 1390 & Pure electric & Compact car \\
\hline Guangqi New energy & 12.9 & 1575 & Pure electric & Compact car \\
\hline Yundu $\pi 3$ & 12.71 & 1470 & Pure electric & SUV \\
\hline Yundu $\pi 1$ & 11.97 & 1410 & Pure electric & SUV \\
\hline
\end{tabular}

Data Source: Pacific Auto Network.

Table A2. China's power structure data in 2018, 2020, 2030, and 2050.

\begin{tabular}{|c|c|c|c|c|}
\hline \begin{tabular}{|ll} 
Power Generation Type & Year \\
\end{tabular} & 2018 & 2020 & 2030 & 2050 \\
\hline Coal power (trillion $\mathrm{kWh}$ ) & 4.45 & 4.506 & 3.789 & 1.59 \\
\hline Hydropower (trillion kWh) & 1.23 & 1.428 & 1.71 & 1.71 \\
\hline Nuclear power (trillion kWh) & 0.29 & 0.377 & 0.78 & 1.5 \\
\hline Gas power generation (trillion $\mathrm{kWh}$ ) & 0.22 & 0.275 & 0.749 & 1.04 \\
\hline Wind power (trillion $\mathrm{kWh}$ ) & 0.37 & 0.581 & 0.86 & 2.589 \\
\hline Solar power (trillion kWh) & 0.18 & 0.166 & 0.86 & 3.256 \\
\hline Biomass power (trillion kWh) & 0.0906 & 0.068 & 0.191 & 0.647 \\
\hline Other thermal power (trillion $\mathrm{kWh}$ ) & 0.16 & - & - & - \\
\hline Total (trillion kWh) & 6.994 & 7.401 & 8.939 & 12.332 \\
\hline
\end{tabular}

Data Source: National Energy Administration "Introduction to the Operation of Renewable Energy Grid-Connected in 2018”, “2018 National Electric Power Process Statistics Express List” issued by China Electricity Council, "National Economic and Social Development of the People's Republic of China 2018" issued by the National Bureau of Statistics Development Bulletin and Power Structure Estimation Based on National Energy and Power Development Strategic Objectives. 


\section{References}

1. Xu, X.P. Spring of new energy automobile industry. Ecol. Econ. 2014, 30, 10-13. [CrossRef]

2. Lin, Z.F. Why does China attach so much importance to the development of new energy automobile industry? Econ. Obs. Available online: https://www.d1ev.com/news/shichang/65018 (accessed on 19 March 2018).

3. Turk, D. Global Electric Vehicle Vision 2018; International Energy Agency: Paris, France, 2018.

4. Palencia, J.C.G.; Otsuka, Y.; Araki, M.; Shiga, S. Scenario analysis of lightweight and electric-drive vehicle market penetration in the long-term and impact on the light-duty vehicle fleet. Appl. Energy 2017, 204, 1444-1462. [CrossRef]

5. Zhou, B.Y. Research on Energy Consumption, Carbon Emission and Cost Benefit of Electric Vehicle Life Cycle; Tsinghua University: Beijing, China, 2016.

6. Shen, W.; Zhang, A.L.; Han, W.J. Comparative study on energy consumption and greenhouse gas emission of alternative fuels for vehicles. Nat. Gas Ind. 2006, 11, 148-152.

7. Shen, W.; Zhang, A.L.; Han, W.J. Comparative analysis of vehicle synthetic fuel energy consumption and greenhouse gas emission. J. Tsinghua Univ. 2007, 3, 441-444.

8. Ou, X.M.; Zhang, X.L.; Qin, Y.N.; Qi, T.Y. Life cycle analysis of future coal-driven electric vehicles. J. Coal 2010, 35, 169-172.

9. Ou, X.; Yan, X.; Zhang, X. Using coal for transportation in China: Life cycle GHG of coal-based fuel and electric vehicle, and policy implications. Int. J. Greenh. Gas Control. 2010, 4, 878-887. [CrossRef]

10. Shi, X.; Wang, X.; Yang, J.; Sun, Z. Electric vehicle transformation in Beijing and the comparative eco-environmental impacts: A case study of electric and gasoline powered taxis. J. Clean. Prod. 2016, 137, 449-460. [CrossRef]

11. Shi, X.Q.; Sun, Z.X.; Li, X.N.; Li, J.Y.; Yang, J.X. Comparative study on the environmental impact of life cycle of electric taxi and fuel taxi in Beijing. Environ. Sci. 2015, 3, 1105-1116.

12. Song, Y.H.; Li, B.W.; Hu, Z.C. Analysis of carbon emission regional characteristics of electric vehicles in China. China Energy 2013, 35, 12-16.

13. Zhang, L.; Liu, Z.F.; Wang, J.J. Comparative analysis of life cycle environmental impact of electric and internal combustion engine vehicles. J. Environ. Sci. 2013, 3, 931-940.

14. Feng, C.; Wang, K.; Xu, Z.Q.; Gong, P.Q. Research on greenhouse gas emission of private electric vehicles based on hybrid life cycle method. Chin. Popul. Resour. Environ. 2017, 27, 178-187.

15. Ellingsen, L.A.W.; Singh, B.; Strømman, A.H. The size and range effect: Lifecycle greenhouse gas emissions of electric vehicles. Environ. Res. Lett. 2016, 11, 54010. [CrossRef]

16. Ellingsen, L.W.A. Life cycle assessment. In Proceedings of the 12th Concawe Symposium, Antwerp, Belgium, 20-21 March 2017.

17. Lu, J.F. Many countries announce that they will ban the sale of fuel cars in the future. Ecol. Econ. 2017, 57-63.

18. Du, G.; Cao, W.; Hu, S.; Lin, Z.Y.; Yang, J.; Yuan, T.J. Assessment of an Electric Vehicle Powertrain Model Based on Real-World Driving and Charging Cycles. IEEE Trans. Veh. Technol. 2018, 11-17. [CrossRef]

19. Pazheri, F.R.; Othman, M.F.; Malik, N.H.; Khan, Y. Emission constrained economic dispatch for hybrid energy system in the presence of distributed generation and energy storage. J. Renew. Sustain. Energy 2015, 7, 013125. [CrossRef]

20. Modaresi, R.; Pauliuk, S.; Løvik, A.N.; Muller, D.B. Global Carbon Benefits of Material Substitution in Passenger Cars until 2050 and the Impact on the Steel and Aluminum Industries. Environ. Sci. Technol. 2014, 48, 10776-10784. [CrossRef] [PubMed]

21. Kim, H.C.; Wallington, T.J. Life-cycle Energy and Greenhouse Gas Emission Benefits of lightweighing in Automobiles: Review and Harmonization. J. Environ. Sci. Technol. 2013, 47, 6089-6097. [CrossRef]

22. Wang, C.B.; Zahng, X.; Pang, M.Y. Review of life cycle evaluation methods-Development and application of hybrid life cycle evaluation. J. Nat. Resour. 2015, 30, 1232-1242.

23. Li, X.H.; Ji, J.P.; Ma, X.M.; Wang, J.T. Research on greenhouse gas emission of fuel ethanol life cycle based on EIO-LCA. J. Peking Univ. 2011, 47, 1081-1088.

24. Joshi, S. Product Environmental Life-Cycle Assessment Using Input-Output Techniques. J. Ind. Ecol. 1999, 3, 95-120. [CrossRef]

25. Suh, S.; Lenzen, M.; Treloar, G.J.; Hiroki, H. The System Boundary Selection in Life-Cycle Inventories Using Hybrid Approaches. J. Environ. Sci. Technol. 2004, 38, 657-664. [CrossRef] [PubMed] 
26. De Souza, L.L.P.; Lora, E.E.S.; Palacio, J.C.E.; Rocha, M.H.; Renó, M.L.G.; Venturini, O.J. Comparative environmental life cycle assessment of conventional vehicles with different fuel options, Plug-in hybrid and electric vehicles for a sustainable transportation system in Brazil. J. Clean. Prod. 2018, 203, 444-468. [CrossRef]

27. IPCC. Climate Change 2013: The Physical Science Basis, Contribution to the Fifth Assessment Report of the Intergovernmental Panel on Climate Change; Cambridge University: London, UK, 2013.

28. Van Sark, W.G.; Schepers, J.G.; van Wees, J.D.A. The Growing Role of Photovoltaic Solar, Wind and Geothermal Energy as Renewables for Electricity Generation. Sustainability Assessment of Renewables-Based Products; John Wiley \& Sons, Ltd.: Hoboken, NJ, USA, 2015.

29. IPCC. 2006 IPCC Guidelines for National Greenhouse Gas Inventories; Institute of Global Environmental Strategy: Kanagawa, Japan, 2006.

30. National Development and Reform Commission. Provincial GHG Inventory Preparation Guide; National Development and Reform Commission: Beijing, China, 2011.

31. National Bureau of Statistic. China Statistical Yearbook 2018. Available online: http://www.stats.gov.cn/tjsj/ ndsj/ (accessed on 30 December 2018).

32. Zhang, L.; Liu, Z.F.; Wang, J.J. Comparative analysis of the environmental impact of the power system life cycle of electric and fuel vehicles. J. Environ. Sci. 2013, 17, 53-64.

33. China National Coal Association. The Research Report of China Coal Industry Development in 2014; China Economic Publishing House: Beijing, China, 2014.

34. Ministry of Transport of the People's Republic of China. China Transport Statistical Yearbook 2015; China Communications Press: Beijing, China, 2015.

35. National Bureau of Statistics of China. China Energy Statistical Yearbook 2015; China Statistics Press: Beijing, China, 2016.

36. China Chemical Energy Saving Technology Association. China Petroleum and Chemical Industry Energy Conservation Report 2014; Chemical Industry Press: Beijing, China, 2015.

37. CNPC Economics and Technology Research Institute. Domestic and Foreign Oil and Gas Industry Development Report 2014; Petroleum Industry Press: Beijing, China, 2015.

38. Shen, W.; Han, W.; Chock, D.; Chai, Q.; Zhang, A. Well-To-wheels life-cycle analysis of alternative fuels and vehicle technologies in China. Energy Policy 2012, 49, 296-307. [CrossRef]

39. Pacific Auto Network. Available online: https://www.pcauto.com.cn/ (accessed on 10 May 2019).

40. National Energy Administration of China. Introduction to the Operation of Renewable Energy Grid-Connected in 2018; National Energy Administration Official Website. Available online: http: //www.nea.gov.cn/ (accessed on 14 February 2018).

41. China Electricity Council. National Electric Power Process Statistics Express List; China Electricity Council Press: Beijing, China, 2018.

42. National Bureau of Statistic. National People's Republic of China 2018 National Economic and Social Development Gazette; China Statistics Press: Beijing, China, 2018.

43. Gao, Y.B.; Mao, X.Q.; Yang, S.Q. Analysis and evaluation of energy-saving and emission reduction effects of new-energy cars based on LCA. J. Environ. Sci. 2013, 33, 1504-1512.

44. Maj, G. Diversification and environmental impact assessment of plant biomass energy use. Pol. J. Environ. Stud. 2015, 24, 2055-2061. [CrossRef]

45. Cholewiński, M. The reduction of atmospheric emissions after the implementation of first Polish nuclear power plant//European Physical Journal Web of Conferences. Eur. Phys. J. Web Conf. 2018, 177, 01001. [CrossRef]

46. Jasiulewicz, M.; Jordan, A. Possibility of liquid bio-fuels, electric and heat energy production from biomass in Polish agriculture. Pol. J. Environ. Stud. 2010, 19, 479-483.

47. Brodzinski, Z.; Kryszk, H.; Kurowska, K. Market of Producers and Processors of Agricultural Biomass for Energy Purposes. Pol. J. Environ. Stud. 2014, 23, 619-627.

48. Gumula, S.; Pytel, K.; Piaskowska-Silarska, M. Environmental and Economic Benefits of Using Kinetic Wind Energy to Generate Electricity. Pol. J. Environ. Stud. 2014, 23, 2315-2320. 
49. Daniel, S.; Piwowarski, M. Analyzing Selection of Low-Temperature Medium for Cogeneration Micro Power Plant. Pol. J. Environ. Stud. 2014, 23, 1417-1421.

50. Liu, Q.; Miao, Q.; Liu, J.J.; Yang, W. Solar and wind energy resources and prediction. J. Renew. Sustain. Energy 2009, 1, 043105. [CrossRef]

(C) 2019 by the authors. Licensee MDPI, Basel, Switzerland. This article is an open access article distributed under the terms and conditions of the Creative Commons Attribution (CC BY) license (http://creativecommons.org/licenses/by/4.0/). 